\title{
EDITORIAL
}

\section{Universidad y liderazgo de servicio}

La universidad debe ser no sólo una corporación de estudiantes y sabios, sino una potencia ética de la vida.

Francisco GINER DE LOS RÍOS

Resumen: Revista de Fomento Social ofrece una reflexión acerca del liderazgo de la universidad como institución y del papel que ésta tiene en la formación de líderes. Partiendo de una mirada crítica sobre las definiciones convencionales del término liderazgo, se enuncian las características del liderazgo ignaciano, ya que escribimos desde una institución inspirada por la Compañía de Jesús, y a continuación se establece la distinción entre misión y funciones de la universidad y se enumeran las oportunidades y amenazas que para el liderazgo universitario supone el establecimiento del Espacio Europeo de Educación Superior.

En la segunda parte del editorial se analiza, por un lado, el papel de la universidad como formadora de líderes sociales $y$, por otro, el rol de la propia universidad como líder institucional en el contexto de la sociedad actual. Éste sólo será posible si los miembros de la comunidad universitaria comparten esta misión.

Palabras clave: cambio social, carisma, EEES (espacio europeo de educación superior), formación de líderes sociales, liderazgollideres, liderazgo de servicio, liderazgo social de la universidad, misión, responsabilidad social universitaria, universidad, virtudes públicas.

Fecha de aprobación: 12 de junio de 2014. 


\section{University and servant leadership \\ Editorial Board}

Abstract: The Editorial Board of the Journal of Social Development offers a reflection on the leadership of the University as an institution and the role it plays in the formation of leaders. Starting with a critical eye over conventional definitions of leadership, characteristics of Ignatian leadership enunciated as we write from an institution inspired by the Society of Jesus, then the distinction between mission and functions of the university is established and listed opportunities and threats for the university leadership involves establishing the European Higher Education Area.

In the second part of the editorial is analyzed, first, the role of the university as forming social leaders and, secondly, the role of the university as an institutional leader in the context of today's society. This is only possible if the members of the university community share this mission.

Keywords: social change, charisma, EHEA (European higher education), training of community leaders, leadership / leaders, servant leadership, social leadership of the university mission, university social responsibility, university, public virtues.

\section{Université et le leadership de serviteur \\ Comité de rédaction}

Résumé: Le comité de rédaction du Journal du Développement social propose une réflexion sur la direction de l'Université en tant qu'institution et le rôle qu'elle joue dans la formation des dirigeants. À partir d'un œil critique sur les définitions classiques de leadership, caractéristiques du leadership ignatien énoncés que nous écrivons dans un établissement inspiré par la Compagnie de Jésus, la distinction entre la mission et les fonctions de l'université estétabli et répertorié opportunités et menaces pour la direction de l'université consiste à établir l'Espace européen de l'enseignement supérieur.

Dans la deuxième partie de l'éditorial est analysée, d'abord, le rôle de l'université comme faisant dirigeants sociaux et, d'autre part, le rôle de l'université comme un chef de file institutionnel dans le contexte de la société d'aujourd'hui. Ce ne est possible que si les membres de la part de la communauté universitaire de cette mission.

Mots clé: changement social, le charisme, l'EEES (de l'enseignement supérieur européen), formation des leaders communautaires, le leadership I dirigeants, le leadership serviteur, le leadership social de la mission de l'université, l'université la responsabilité sociale, universitaires, vertus publiques. 


\section{Liderazgo: término actual para una realidad antigua y ambigua'}

La palabra liderazgo está de moda. Ahora bien, si el término es reciente, un préstamo del inglés, leadership, que ha acabado imponiéndose pues designa un hecho consistente y muy relevante de nuestro tiempo, la realidad que hay detrás es antigua y en gran medida ambigua. En efecto, los liderazgos han marcado los grandes hitos de la historia humana. Los "padres fundadores" de una Europa más unida o Martin Luther King en su lucha contra la segregación racial, el compromiso heroico de Nelson Mandela contra el "apartheid" en Sudáfrica o la movilización pacifista de Gandhi por la independencia de la India son ejemplos estelares en esa historia humana, como en otro orden puedan serlo el liderazgo científico de Albert Einstein, el comienzo del olimpismo de Pierre de Coubertin o, por añadir tan sólo otros dos nombres de movimientos colectivos, el ejemplo de las madres de la Plaza de Mayo o la lucha por el voto femenino de las sufragistas inglesas. ${ }^{2}$ Es cierto que no han faltado en esta historia humana las sombras, aquellos a quienes podríamos considerar malos líderes, que tantas veces provocaron efectos destructivos o contrarios al bien común humano. No los ignoramos, pero no es de esos líderes de quienes queremos escribir en este editorial.

\footnotetext{
1 Como en otras ocasiones, este editorial es el resultado de un primer seminario interno del Consejo de redacción tenido el 6 de marzo de 2014 a partir de la disertación de un miembro del mismo y de las reuniones del mismo de 15 de mayo y de 12 de junio, día en que quedó finalmente aprobado.

${ }^{2}$ Como ejemplo de personas que han sido líderes o han ejercido un liderazgo humanitario, político o social, anotamos una lista de premios "nobel" de la paz de los últimos veinticinco años, quizás algunos de entre los menos conocidos, lo que nos puede llevar a pensar que con frecuencia echamos en el olvido liderazgos que han sido decisivos: Aung San Suu Kyi, que trabajó de forma no violenta por la democracia y los derechos humanos en Birmania; Frederik Willem de Klerk, que trabajó para el fin pacífico del régimen de "apartheid" y por sentar las bases para una nueva Sudáfrica democrática; Joseph Rotblat, que hizo esfuerzos para disminuir el papel desempeñado por las armas nucleares en la política internacional y, a largo plazo, para eliminarlas; Carlos Felipe Ximenes Belo y José RamosHorta, por su trabajo para una solución justa y pacífica de la independencia de Timor oriental; Jody Williams con su contribución a la prohibición de las minas antipersona; Shirin Ebadi, por sus esfuerzos por la democracia y los derechos humanos, especialmente de las mujeres y los niños; Wangari Muta Maathai, por su contribución para el desarrollo sostenible, la democracia y la paz; Martti Ahtisaari, por sus importantes esfuerzos para resolver los conflictos internacionales; Liu Xiaobo y la lucha no violenta y duradera por defender los derechos humanos fundamentales en China; Ellen Johnson-Sirleaf, Leymah Gboweey y Tawakkul Karman, por su lucha no violenta por la seguridad de las mujeres y los derechos de las mujeres a la plena participación en la obra de construcción de la paz y, finalmente, Malala Yousafzai y Kailash Satyarthi por su lucha contra la represión de los niños y jóvenes y por el derecho de todos los niños a la educación. No son más que una muestra pequeña, pero tal vez suficientemente ilustrativa de que para llevar adelante causas difíciles en pro del bien común humano nos hacen falta personas como las mencionadas, necesitamos líderes.
} 
Hoy se habla de líderes en los campos más diferentes, políticos como académicos, o incluso deportivos. Pero iparadójicamente! tampoco faltan voces que deploran la falta de auténticos líderes, al menos los que nuestra actual situación parece reclamar. Estamos en un momento de transición crítica, que aún nos cuesta comprender adecuadamente. Los cambios tecno-científicos y demográficos están provocando consecuencias aún difíciles de interpretar, pero probablemente estemos asistiendo a modificaciones paradigmáticas en nuestra comprensión de la realidad y de la misma condición humana. La mundialización económica (principalmente la globalización financiera y, parcialmente, la comercial), los movimientos migratorios, el desarrollo tecnológico, las consecuencias medioambientales de la sobreexplotación de la tierra, la generalización acumulativa y creciente exponencialmente de la comunicación en la llamada sociedad-red, etc. forman parte de este cambio de época en el que ya han empezado a tambalearse las estructuras sociales que nos eran conocidas, pero aún no hemos encontrado las nuevas formas de "ordenar" y representarnos el mundo. En esos "tiempos líquidos" las interpretaciones son débiles, los mensajes cambiantes, y por ello echamos en falta, aún más, líderes auténticos que puedan proponer horizontes saludables de vida digna y justa para todos. Estas etapas de transición se caracterizan por la incertidumbre, la inseguridad e incluso el miedo, aunque también sean momentos en los que los más audaces e imaginativos van abriendo camino hacia un nuevo orden. Esta necesidad de afrontar los nuevos retos va acompañada de la búsqueda de referentes, líderes con visión, capaces de inspirar y aportar algo de certeza en este contexto de transición en que vivimos, en sociedades plurales donde tantas veces faltan referencias éticas compartidas y domina una cierta indefinición, rayana en la desorientación si no en el escepticismo, el relativismo o las más desmoralizante pasividad conformista.

Al escribir en este editorial sobre liderazgo no pretendemos tratar sobre éste en general, sino más concretamente sobre el liderazgo en relación con la formación universitaria. Nos proponemos, pues, dos órdenes de cuestiones: uno sobre el papel que corresponde a la universidad como formadora de líderes. ¿̇Es misión de la universidad la formación de líderes? ¿̇está dentro de sus fines?

Por otro lado, nos gustaría aportar una reflexión válida sobre el papel de la universidad como líder social, puesto que entendemos que los liderazgos no son sólo personales, sino también institucionales o de grupos sociales enteros. Ha habido incluso distintos momentos en la historia en que unos $u$ otros países han liderado los procesos históricos. Más aún, queremos acercarnos al tema del liderazgo en relación con la universidad desde la aportación de la tradición ignaciana. Tampoco hoy faltan los estudios sobre liderazgo ignaciano, lo que muestra que el tema interesa desde perspectivas muy diferentes. 


\section{El contenido del liderazgo, pero ¿qué liderazgo?}

Lo primero que hay que hacer, como ocurre siempre que algún concepto se pone de moda, es precisar su contenido. Porque hoy la palabra liderazgo se usa con contenidos no siempre coincidentes y con una cierta ambigüedad, que tiende a incluir dentro del concepto liderazgo aspectos demasiado diversos.

Para algunos, el propio término liderazgo no es sino un ejemplo más del predominio invasivo de la lengua inglesa y de una determinada tendencia individualista neo-liberal que, como ocurre en los ecosistemas de la naturaleza, parece actuar a modo de "especie exótica invasora" que reemplaza a la "especie autóctona". Aun aceptando que quizás haya palabras más adecuadas, no vamos a discutir el término, pues preferimos centrarnos en el significado que para el propósito de este editorial creemos debe darse al liderazgo. El liderazgo, sirviéndonos de la distinción clásica, se ejerce más desde la auctoritas, desde la capacidad emocional y las habilidades sociales, que obviamente desde la potestas, la capacidad organizativa y el control coercitivo.

Se suele considerar que el liderazgo tiene que ver con la función de dirección; otras veces tiende a identificarse al líder con una persona dotada de autoridad. Pero habría que decir que el liderazgo podría formar parte de las tareas directivas, aunque ésta se fija más en las tareas y en los objetivos, mientras que el liderazgo se centra más en la persona y en los procesos. En cuanto a la gestión, suele afirmarse que liderazgo y gestión son dos sistemas distintos y complementarios, ambos necesarios para el funcionamiento de una organización, pero cada uno tiene su función propia y rasgos distintivos: la gestión tiene que ver con la planificación, el control y la puesta a punto de las estructuras apropiadas, mientras que el liderazgo tiene que ver más con la anticipación al cambio, afrontando el mismo desde una "visión" 3 . Los líderes crean visión, participan de los valores y estrategias al mantener la vista en el horizonte, mientras que los administradores organizan, controlan y planifican manteniendo la vista en el suelo.

Es clásica también la distinción entre liderazgo transaccional y liderazgo transformacional. La base del primero es el proceso de intercambios y acuerdos entre los líderes y sus seguidores. El líder transaccional reconoce las necesidades y los deseos de los seguidores y, después, explica con claridad cómo podrán satisfacerse esas necesidades y deseos, a cambio de que se cumplan los objetivos especificados en

${ }^{3}$ Así lo formuló uno de los clásicos del liderazgo, John Kotter, por ejemplo en "What do leaders really do?": Harvard Business Review 68 (1990). 
la realización de ciertas tareas. Los seguidores reciben premios por su desempeño laboral y el líder se beneficia porque, al cumplir aquellos con las tareas, se logran los objetivos de la organización. Se consigue así que la organización funcione sin problemas y con eficiencia. En el liderazgo transformacional, en cambio, el énfasis se pone en la visión, en la capacidad del líder para hacer que los otros compartan sus sueños mientras que dejan en segundo término sus intereses propios para cooperar en la marcha de la organización. El líder transformacional tiene, por tanto, la capacidad de modificar la escala de valores, las actitudes y las creencias de los seguidores.

Pero cabe dar un paso más. En un mundo tan plural como es el nuestro, ¿̇cuáles son las virtudes que podemos compartir? Nos parece claro que no han de ser sólo valores formales o procedimentales como son el respeto, la tolerancia o la disposición a la interlocución, sino que podemos compartir valores sustantivos, de contenido, como son la justicia, la libertad, el diálogo o la solidaridad. Por esta razón, no debemos contentarnos con entender el liderazgo únicamente desde una perspectiva técnica o instrumental, como una mera habilidad relacional que requiere tan sólo el desarrollo de unas competencias, sino que hemos de preguntarnos al servicio de qué fines se ponen esas habilidades instrumentales. Pasamos de este modo de la pregunta por el liderazgo a la pregunta por el buen liderazgo. Surge entonces el concepto de liderazgo responsable.

Para describir este tipo de liderazgo responsable -afirma Josep Maria Lozano-

se apela a parámetros eminentemente cualitativos, en el marco de un enfoque relacional: el líder debe cuidar de los valores compartidos, de las comunidades en las que actúa; servir a los demás, y ofrecer inspiración y perspectiva sobre el futuro deseado. Para ello debe convertirse en arquitecto de estructuras y procesos, agente del cambio transformador; dar apoyo a sus seguidores, y crear sentido y significado ${ }^{4}$.

Una concepción tan ambiciosa del liderazgo ha llevado a algunos autores a preguntarse si es posible exigirlo a una sola persona: por eso se habla hoy con frecuencia de liderazgo, más que de líder. Otros expresan esta clave para entender lo que es el liderazgo: entender la realidad de manera que pueda anticiparse en el presente lo que está llamado a ser en el futuro 5 .

${ }^{4}$ J. M. Lozano (2011) "Liderazgos, no líderes. Los Ejercicios Espirituales y las escuelas de negocios", Revista de Fomento Social 66, 187. También puede verse J. M. GUIBERT (2014) Diccionario de liderazgo ignaciano, Bilbao, Mensajero, 343 pp.

5 O. C. Scharmer (2009) Theory U. Learning from the Future as It Emerges. Cambridge, Berrett-Koehler. 
Resumiendo la panorámica precedente, breve e incompleta, pensamos que nuestro mundo está demandando un liderazgo transformacional, más que transaccional, y un liderazgo responsable (de compromiso con una misión, no de árbitro imparcial). Y añadiríamos todavía un liderazgo de servicio (servant leadership), que pone el acento más en el servicio que en el liderazgo mismo y que se preocupa, ante todo, por saber al servicio de qué se pone el liderazgo.

De acuerdo con este planteamiento, si el liderazgo es la capacidad para implicar a otros en un proyecto compartido orientado al futuro, los distintos tipos de liderazgo que se pueden identificar dependen de la combinación entre el tipo de proyecto y la forma en que el líder es capaz de implicar a las personas.

En este editorial nos interesa sobre todo ese tipo de liderazgo de servicio, que pone el acento en la capacidad de servicio y no en el éxito personal, profesional o institucional. Este liderazgo de servicio es el auténtico motor para una transformación social hacia un mundo más libre, solidario y justo, mientras que otros liderazgos contribuyen a perpetuar el desorden establecido. Una universidad que estuviese sólo al servicio del sistema como reproductora de fuerza cualificada de trabajo sería más sensible a los liderazgos emprendedor y transaccional, necesario pero no suficiente a nuestro juicio. Las humanidades y la razón crítica y cordial abren a una reflexión sobre un liderazgo transformador y responsable.

\section{Liderazgo ignaciano}

Un proyecto educativo inspirado por la misión y la espiritualidad jesuitas propone como compromiso de responsabilidad social una formación en cuatro dimensiones: competencia profesional, humanismo integral abierto, compromiso social y capacidad hermenéutica de comprensión e inteligencia social ${ }^{6}$.

El liderazgo de servicio, la concepción de liderazgo que proponemos, se enraíza hondamente con la tradición ignaciana y jesuita. Es bueno recordarlo aquí porque estamos reflexionando y escribiendo sobre liderazgo y universidad desde una institución inspirada por la Compañía de Jesús. No es que en los textos de San Ignacio o de la primera Compañía se hablase expresamente de liderazgo, pero no cabe duda que el liderazgo de servicio está en profunda sintonía con algunos elementos muy presentes en la tradición jesuita.

${ }^{6}$ Cf. J. M. Margenat (2010) Competentes, conscientes, comprometidos y compasivos. La educación de los jesuitas, Madrid, PPC. 
En un reciente y difundido libro sobre el liderazgo de los jesuitas, su autor ha querido poner de relieve cómo en la tradición ignaciana hay rasgos que concuerdan perfectamente con lo que hoy se entiende por liderazgo. En esa obra se atreve a identificar los que él considera cuatro pilares del liderazgo de los jesuitas: autoconciencia (conscientes de las propias fuerzas, debilidades, valores y visión del mundo, gracias a un hábito de autorreflexión y aprendizaje continuo), ingenio (siempre dispuestos a innovar y adaptarse a un mundo en constante cambio, confiadamente y sin asustarse de las sorpresas que puedan salirles al paso), amor (comprometidos con otros con una actitud positiva y bondadosa, capaz de descubrir el potencial de los otros y ayudarles a desarrollarlo) y heroísmo (capaces de fomentar grandes deseos, construir proyectos ambiciosos y llevarlos adelante sin temor a las dificultades)?

La literatura sobre la aportación que la espiritualidad ignaciana puede significar para ese liderazgo responsable de servicio, que tanto se demanda hoy, es abundante. Aquí nos vamos a limitar a extraer algunos elementos de dicha tradición que pueden ayudarnos a comprender de qué liderazgo hablamos cuando nos referimos a centros universitarios de inspiración ignaciana y jesuita.

1) La centralidad de la misión. En la Compañía de Jesús la misión es indiscutiblemente la razón de ser de toda su vida, su actividad y sus instituciones, que no son más que un medio, nunca un fin. A diferencia de otras organizaciones, una institución de la Compañía de Jesús no tiene su fin en su propio éxito, sino en los resultados que ejerce fuera de ella, en el servicio prestado a otros. Si ése es el contenido material de la misión, el objeto formal que la define es la mayor gloria de Dios, identificable con el reinado de Dios y su justicia.

2) Esta única misión tiene una doble expresión integral (religiosa y social): facilitar la relación del ser humano con Dios y trabajar para hacer un mundo más humano y más justo, y por ello más divino. La definición del carisma propio que hizo la Compañía de Jesús en 1975 lo expresó claramente: "el servicio de la fe y la promoción de la justicia" (que brota de ese anuncio y forma parte integrante de él). No se trata de dos tareas separadas, sino de dos aspectos de la misma misión, al servicio de la cual ha de estar también una institución universitaria jesuita.

${ }^{7}$ Cf. C. Lowney (2005) El liderazgo de los jesuitas. Autoconciencia, ingenio, amor, heroísmo, Sal Terrae, Santander 2014, 37-47. El libro había sido publicado en Estados Unidos en 2003 y traducido ya al castellano, habiendo sido editado en Colombia y en España sucesivamente por Granica, Norma y Verticales de bolsillo. Cfr. J. J. Romero Rodríguez (2006) (Bibliografía): Revista de Fomento Social 61, 686-688; el mismo autor ha publicado recientemente Francisco, líder y Papa, Santander 2014, Sal Terrae (original de 2013, con el significativo título Pope Francis: why he leads the way he leads: lessons from the first jesuit Pope). 
3) El papel de los Ejercicios espirituales, un método que san Ignacio descubrió desde su experiencia de seglar peregrino y buscador del sentido último de su vida y de lo que Dios quería de él, que luego ofreció a otros compañeros y compañeras, seglares como él. Su objetivo es la búsqueda de la voluntad de Dios sobre quien los práctica, pero lgnacio ofrece un método que ayuda al ejercitante para conocerse mejor, sospechar de sus propios sentimientos y purificarlos y ponerse en una actitud de verdadera y radical libertad. Se trata, por tanto, de una experiencia personal de Dios que implica toda la vida del que entra en esa relación. Los Ejercicios son un método, pero engendran también una espiritualidad y una forma de entender a la persona en lo más hondo de su relación con Dios.

4) La atención a las personas, como centro de cualquier proceso formativo y de toda estrategia institucional. Este elemento es el presupuesto esencial de los Ejercicios espirituales y del valor que san Ignacio les atribuyó en su vida. No se trata de formar según un estereotipo, sino de acompañar a cada uno en un proceso que es siempre personal y debe ser entendido de forma personalizada. $Y$ no se trata tampoco de instrumentalizar a las personas, sino de abrirlas a los horizontes de sentido que enmarquen su ejercicio de la libertad y de la responsabilidad.

5) La búsqueda del magis, ese adverbio que tanto repetía san Ignacio, y que lo concretaba en la mayor gloria de Dios, el mayor servicio del prójimo, el bien más universal, los medios apostólicos más efectivos.

6) La unión de los ánimos, otra de las preocupaciones de san Ignacio, que no quería tanto estructuras de convivencia al estilo de las que tenían otras órdenes religiosas de su tiempo, sino que todos compartiesen un mismo espíritu y un mismo sentir.

7) Estar en las fronteras, como reconoció y elogió el papa Benedicto XVI cuando se encontró con los jesuitas, reunidos en la última Congregación general (2008), a los que dijo que las fronteras son un terreno difícil, según expresaron también la propia Congregación general o Adolfo Nicolás, superior general de la Compañía de Jesús:

No son los mares o las grandes distancias los obstáculos que desafían hoy a los heraldos del Evangelio, sino las fronteras que... acaban alzándose entre la fe y el saber humano, la fe y la ciencia moderna, la fe y el compromiso por la justicia. Por eso la Iglesia necesita con urgencia personas de fe sólida y profunda, de cultura seria y de auténtica sensibilidad humana y social (Benedicto XVI),

lo que la Congregación formuló así:

... la tarea de la confrontación y del diálogo con los muy diversos contextos sociales y culturales y las diferentes mentalidades del mundo actual se revela como una de las más 


\begin{abstract}
difíciles y laboriosas. Y esa búsqueda de la calidad y de la solidez humana, espiritual y cultural, deberá caracterizar también a toda la múltiple actividad formativa y educativa de los jesuitas, doquiera se encuentren, a favor de los más diversos tipos de personas.

Cuando el Papa nos envía a las fronteras y a los sitios más difíciles y nos pide un diálogo con las culturas, la ciencia y las religiones, él sabe más que nadie que vamos a tener conflictos, malentendidos, acusaciones y ataques. Pero eso no nos preocupa; llevamos 450 años de experiencia. Lo que sí nos preocuparía es si, por nuestra propia seguridad o comodidad, dejáramos de servir a la lglesia y al mundo, con todos los riesgos que lleva consigo la búsqueda profunda y el diálogo de las fronteras. (...) Para ir a las fronteras se necesita gente con una fe muy profunda, bien arraigada y cultivada. En este contexto, es importante el sentido de ser un cuerpo, el sentido de Compañía, que no por casualidad es nuestro nombre (Adolfo Nicolás).
\end{abstract}

Esta breve evocación de rasgos de la tradición ignaciana, que la Compañía de Jesús ha querido inspire sus instituciones, es útil para comprender que el concepto mismo de liderazgo puede enriquecerse y dotarse de una indudable calidad desde la inspiración ignaciana.

\title{
4. Universidad y formación de líderes
}

Decía Francisco Giner de los Ríos que la universidad debía ser "no sólo una corporación de estudiantes y sabios, sino una potencia ética de la vida" ${ }^{8}$. Después de haber considerado diversas concepciones del liderazgo y enunciado las características del liderazgo ignaciano, iniciamos la reflexión acerca del liderazgo de la universidad como institución y el papel que ésta tiene en la formación de líderes. Si nos limitásemos a pensar que la universidad se reduce al primer miembro enunciado por Giner, posiblemente no podríamos añadir mucho más, nos bastaría remitirnos a una paideia que formase en la ejemplaridad personal. No habríamos de desdeñar demasiado pronto que ésta sea una de las claves esenciales de una formación para el liderazgo, aunque no sea la que aquí priorizamos. En una cultura post-nihilista las virtudes públicas personales son un camino privilegiado para aquella formación, realizable en una sociedad igualitaria, democrática y secularizada, que es deseable y necesaria?.

${ }^{8}$ F. GINER DE LOS Ríos (1916) Obras completas, Madrid, Espasa Calpe, v. 2, 131, reproducido en F. GINER DE LOS Ríos (1969) Ensayos, Madrid, Alianza, 137, y en F. GINER DE LOS Ríos (1997) Obras completas (edición de T. Rodríguez de LeCEA), Madrid, Fundación CajaMadrid, v. 3, 165.

9 Cfr. J. Gomá Lanzón (2014) Ejemplaridad pública [2009], Madrid, Taurus. Cfr. V. Camps (1990) Virtudes públicas, Madrid, Espasa-Calpe. 


\section{I.Amenazas y oportunidades en el actual contexto europeo}

Un análisis del panorama universitario español permite identificar universidades con programas específicos de formación en liderazgo al lado de universidades que, al menos explícitamente, no la han incorporado aún a sus programas. La constatación de este hecho pone de manifiesto que es necesario distinguir entre misión y funciones de la universidad. Mientras que la misión debe situarse en un plano superior y fundante, digamos también finalista e institucional, merced a la irrenunciable tradición de la institución universitaria, la formación para el liderazgo parece compadecerse mejor como una función más entre otras, encomendada legal o reglamentariamente o asumida libremente por la universidad.

La posibilidad y la conveniencia de que la universidad asuma la formación de líderes se encuentra hoy favorecida y amenazada al mismo tiempo por algunas condiciones de nuestro tiempo.

La oportunidad más significativa viene encarnada por el Espacio Europeo de Educación Superior (EEES). Éste abre nuevas posibilidades, ante todo, por la libertad que otorga a los centros: los planes de estudios ya no se configuran como antes, cuando la administración pública educativa definía prácticamente la totalidad de sus contenidos para cada titulación. Al permitirse ahora a cada universidad diseñar sus propios planes de estudios, dentro de ciertas coordenadas, se hace posible que encontremos graduados en Administración y dirección de empresas o en Derecho o Ingenieros con perfiles profesionales distintos según la universidad que los formó, porque cada universidad puede poner sus propios "acentos".

Otra novedad del EEES se presenta como una excelente oportunidad: la formación no está ceñida sólo a la transmisión de conocimientos, sino que ha ampliado su objetivo a la formación en competencias y habilidades que el estudiante debe alcanzar en su proceso formativo. Sabemos de las dificultades que representa esta ampliación de objetivos formativos con el desarrollo programado de capacidades y actitudes. Pero, además de estas dificultades, es indudable que éste, por la tarea y por la inercia aún persistente, es un reto para que la formación universitaria sea más integral y, por ende, más humana.

Este enfoque, que incorpora la universidad europea por medio del EEES, viene a coincidir con la demanda formulada por diferentes organizaciones internacionales. Nos limitamos a recordar la invitación reiterada por una institución tan relevante en este campo como es la UNESCO. En su Conferencia Mundial sobre Educación Superior en el siglo XXI (1998), y, en concreto, en el "Proyecto de Declaración 
mundial sobre la Educación Superior en el siglo XXI", reconoce como misión de este nivel educativo formar profesionales capacitados que actúen como ciudadanos responsables, competentes y comprometidos con el desarrollo social. Lo anterior queda refrendado tanto en el Comunicado de Londres (2007) como en el Comunicado de Leuven / Louvain-la-Neuve (2009), en los que se reconoce el papel de las instituciones de enseñanza superior en la definición y transmisión de los valores sobre los que se han construido nuestras sociedades, afirmando que

las políticas de educación superior deberían enfocarse a maximizar el potencial de las personas en cuanto a su desarrollo personal y su contribución a una sociedad sostenible, democrática y basada en el conocimiento,

lo que requiere competencias éticas y específicas que lo permitan ${ }^{10}$.

Por otra parte, el contexto de la "sociedad del conocimiento", en el que la información no sólo es abundante sino también fácilmente accesible, invita también a replantear la función de la universidad, pues ya no tiene tanto sentido que su función exclusiva sea la trasmisión del conocimiento. Esta función universitaria debe ser complementada por un modelo más ambicioso de formación superior, en el que la función principal sea enseñar a valorar, organizar, interpretar, seleccionar, estimar, criticar y asumir con criterios del porqué y del para qué la información. En este nuevo contexto, el reto de las universidades es asumir este modelo de formación integral, que adquiere mayor significación para que los futuros profesionales puedan interpretar el entorno. Los nuevos horizontes del EEES están en armonía con este reto.

Pero también hay que hablar de amenazas, que han aparecido y han sido denunciadas en el contexto de esta reforma europea de la educación universitaria. Se ha criticado, y con razón, que dicho proyecto está demasiado condicionado por las necesidades y las exigencias del mercado laboral, por los imperativos derivados de la productividad, la relación coste-beneficio, etc., hasta el punto de desvirtuar los valores esenciales que deben caracterizar a la institución universitaria. ${ }^{11}$

10 UNESCO (2007) Towards the European Higher Education Area: responding to challenges in a globalised world, London, 18-V-2007; UNESCO (2009) The Bologna Process 2020 - The European Higher Education Area in the new decade, Conference of European Ministers Responsible for Higher Education, Lovaina, (Bélgica), 28/29-IV-2009.

${ }^{11}$ H. LEWIS (2006) Excellence Without a Soul: How a Great University Forgot Education, Nueva York, Public Affairs, $305 \mathrm{pp}$. El autor analiza cómo las universidades de élite americanas, entre ellas Harvard, se han desviado de su misión y su visión. 
Las universidades españolas sufren estas mismas amenazas, acrecentadas además por la situación de crisis, los recortes presupuestarios y la precariedad laboral de gran parte del personal docente e investigador, especialmente los más jóvenes. Raro es el día que los medios no nos suministran datos sobre tensiones y enfrentamientos del personal universitario con las autoridades universitarias y de éstas con las administraciones publicas.

\subsection{Antes que la formación de líderes, formación en virtudes públicas}

Aunque nuestra última pregunta se refiera a la formación para el liderazgo en la universidad, la educación en las virtudes públicas es el paso previo. Por lo dicho en el apartado anterior creemos que queda claro que las nuevas condiciones en que se desarrolla la educación universitaria son una oportunidad para ésta, que desde hace años se viene proponiendo que la exigencia de comportamientos cooperativos, la participación de la vida pública y la convicción de interés por la vida común, formen parte de una educación en las virtudes públicas propias de una democracia responsable y avanzada.

La formación en valores tiene que ver con la formación ética. Y ésta no debe reducirse a una asignatura dedicada expresamente a ello. Hoy existe frecuentemente una asignatura con ese enfoque que va encontrado cada vez más acomodo en los curriculum universitarios, de lo que nos felicitamos, pues creemos que son válidas las razones por las que la universidad debe anidar la formación ética de los futuros profesionales: porque los dilemas éticos surgen en todas las áreas funcionales de una organización; porque si una institución universitaria evita esta formación, indirectamente está trasladando la idea de que la ética no es una prioridad y porque la negativa a formar en estos aspectos tendría como consecuencia la aceptación por los estudiantes de modelos de liderazgo imperfectos ${ }^{12}$.

La incorporación de la ética como una materia autónoma y diferenciada se está produciendo con grandes diferencias entre unos estudios y otros. Allí donde predominan las ciencias de salud, este tipo de formación ha estado tradicionalmente más presente. En cambio, en las ciencias sociales y, en concreto en los estudios en Administración de empresas, muchas universidades no han sido proactivas, sino más bien reactivas: algunas asignaturas de Ética y/o Deontología profesional se han ido incorporando, o recuperando, poco a poco, en las distintas titulaciones,

${ }^{12}$ M. ValenZuela (2011) “Developing a Business Ethics Curriculum for the bachelor of science in Accountancy students of De la Salle University": Journal of Modern Accounting and Auditing 7, 1179-1189. 
aunque muchas veces sólo como asignaturas optativas, a veces bajo el título de Responsabilidad social o similares.

Todo esto nos estimula a dar un paso más. La dimensión ética nos parece tan relevante, en sí misma considerada y como reacción frente a una sociedad donde existen comportamientos éticamente poco aceptables, que pensamos que una asignatura de Ética no basta. Sería deseable, y necesario, que la ética sea una dimensión que aparezca en todas las materias que se cursan, una dimensión formativa "transversal", una preocupación de cualquier formador. Chocamos aquí con la postura de quienes piensan que los científicos deben reducirse al rigor de lo objetivo y no dejarse condicionar por juicios de valor. Honestamente, pensamos que esa pretendida neutralidad es más que discutible y que oculta muchas veces opciones éticas que no se quieren reconocer, y por otra parte, una reducción empírica y cuantitativamente objetiva no es sino la peor de las falsificaciones que impediría a quien la practicase conocer la realidad en toda su complejidad, o sólo le posibilitaría conocer y explicar partes mínimas, pretendiendo que sean la totalidad de lo real. Los presupuestos epistemológicos de una antropología integral y de una comprensión no reductiva de la realidad están postulando desde la razón crítica y emancipatoria que todo el proceso de formación universitaria se vertebre desde la ética como dimensión formativa "transversal" para estudiantes y profesores. El documento Orientaciones identidad y misión (I+M). Ante los nuevos desafíos universitarios. Documento-marco de UNIJEs ${ }^{13}$ postula un humanismo personalista y social como base de la formación universitaria que nos parece expresa bien esta antropología integral crítica que es más amplia que un conjunto de asignaturas de Ética en las distintas titulaciones.

Pero no queremos detenernos en esta cuestión, sino tan sólo reiterar nuestra convicción de que la ética, y no solo las asignaturas de Ética, debe estar presente en la formación que se imparte en la universidad. Remitimos a un editorial anterior de nuestra revista en que nos extendimos sobre esta cuestión, sobre su necesidad y sus dificultades ${ }^{14}$.

\footnotetext{
${ }^{13}$ Cfr. Revista de Fomento Social 63 (2008) 741-762.
}

${ }^{14}$ CONSEJO de REDACCIÓN (2012) "Sentido de la formación ética en la universidad": Revista de Fomento Social 67, 191-210. Desde el año 2001 han aparecido en la colección "Ética de las profesiones" de UNIIES (antes COCESU), publicada por Desclée de Brouwer (Bilbao), 14 volúmenes, el primero dedicado a Temas básicos y el último a Ética de las finanzas, abarcando algunos aspectos generales y once monografías de Éticas de diferentes profesiones. 


\subsection{La formación de líderes, una tarea compleja}

Si la formación en valores nos parece un componente incuestionable de toda formación universitaria, nos preguntamos ahora si esa misma exigencia debería extenderse a la formación para el liderazgo.

Dos constataciones iniciales. Primera: de hecho está presente, y no sólo en la docencia, sino también como objeto de la investigación. En el aspecto docente, son muchas las universidades y los centros de post-grado que han desarrollado programas específicos de formación en liderazgo; por citar algunos ejemplos: el programa ESADE-PwC de Liderazgo Social para Organizaciones no Lucrativas o el Programa de liderazgo universitario ignaciano de las universidades vinculadas a AUSJAL (Asociación de Universidades de la Compañía de Jesús en América Latina). Segunda: estos ejemplos remiten más bien a cursos específicos, mientras que a nosotros nos interesa la formación que debe estar presente en la docencia normal.

Pero volvamos a la pregunta: ¿̇debe ser objetivo de la formación universitaria el desarrollo de las cualidades propias del liderazgo? La complejidad del tiempo que vivimos parece demandarlo así. Si el líder se concibe como un agente de cambio, no cabe duda que la universidad prestaría una valiosa contribución a una sociedad tan necesitada de cambios como la nuestra. Esto implicaría que el liderazgo es cuestión de formación, de adquisición de las competencias y habilidades requeridas y de este modo parecería quedar resuelto el debate sobre si el líder nace o se hace. Probablemente la cuestión es más compleja: aunque hay mucho de formación, ciertas cualidades o disposiciones naturales parecen al menos convenientes porque sobre ellas se puede desarrollar mejor esa capacitación para el liderazgo. Y el hecho de que se den muchos cursos, con rango universitario o sin él, para la formación de líderes, parece presuponer que se trata de una tarea diferente que requiere iniciativas diferentes.

Por otra parte, sería ingenuo pensar que todos los estudiantes que llenan las aulas de las universidades van a ser el día de mañana líderes sociales. La universidad tiene que formar profesionales competentes y honestos, responsables en su actividad y conscientes de su función social, pero ¿̇siempre han de ser líderes?

En el mundo actual sería deseable que la universidad asumiera libremente la responsabilidad de potenciar el liderazgo entre sus alumnos. No como una obligación para todos, pero sí como un horizonte a desplegar ante todos y a fomentar en aquellos mejor dispuestos para esta dimensión de la profesión. Para 
ser un buen profesional no es indispensable ser un líder social, pero muchos profesionales poseen unas competencias que les capacitan para ejercer funciones de liderazgo. Ese liderazgo puede orientarse al ámbito de la propia profesión, pues todo profesional encuentra ocasiones en su vida para ejercer cierto liderazgo, pero puede también abrirse a otros campos como el compromiso social o el servicio político.

Es cierto que este planteamiento parece chocar con la idea de que la universidad debe centrarse exclusivamente en la formación científico-técnica. Pero este enfoque no nos parece realista, ni tampoco responsable. De nuevo aquí la tradición educativa jesuita viene en apoyo de esta posición que adoptamos. Baste recordar el "paradigma Ledesma-Kolvenbach", que pretende inspirar toda la formación universitaria. El jesuita Diego de Ledesma fue un teólogo jesuita español del siglo XVI, profesor del Colegio Romano (actual Universidad Gregoriana) que trabajó en la elaboración de la Ratio Studiorum (un documento que define el modelo de los estudios a promover en los centros de la Compañía de Jesús. Fue el padre Peter-Hans Kolvenbach, superior general de los jesuitas entre 1983 y 2008, quien enunció un modelo cuatridimensional en estos cuatro términos, síntesis de cuatro dimensiones de la formación: utilitas (competencia profesional), iustitia (compromiso social), humanitas (desarrollo integral de la persona) y fides (apertura a la trascendencia y al encuentro con Dios). Kolvenbach tomaba esta fórmula cuatrimembre de un documento elaborado por un grupo de universidades de la Compañía de Jesús en Estados Unidos:

1) es eminentemente práctica, concentrada en proveer a los estudiantes con el conocimiento y las habilidades para sobresalir en cualquier campo que elijan;

2) no solamente es práctica, sino que se preocupa también de los temas de valores, con la educación de hombres y mujeres como buenos ciudadanos y buenos líderes, preocupados por el bien común, y capaces de usar su formación para el servicio de la fe y la promoción de la justicia;

3) celebra el conjunto total del poder y logros intelectuales humanos, al afirmar con confianza la razón, no como opuesta a la fe, sino como su necesario complemento;

4) coloca firmemente todo lo que hace en el contexto de una comprensión cristiana de la persona humana, como criatura de Dios, cuyo fin último trasciende lo humano ${ }^{15}$.

${ }^{15}$ P. H. KolveNBACH (2008) "Discurso al Consejo Directivo de la Universidad de Georgetown", en P. H. KOLVENBACH (2008) Discursos universitarios, Provincia de España de la Compañía de Jesús y UnIJES, Madrid 2008, 259. Una exposición detallada de dicho paradigma Ledesma-Kolvenbach puede verse en: $M$. AgúNDEZ AgúNDEZ (2008) "El paradigma universitario Ledesma-Kolvenbach": Revista de Fomento Social $63,603-631$, y en todo el número monográfico dedicado al mismo, $n^{\circ} 252$, octubre-diciembre. 
Es evidente que una formación concebida según estos parámetros, estimula la dimensión de liderazgo y suministra elementos para desarrollar cualidades del que hemos llamado liderazgo de servicio, liderazgo de calidad, liderazgo responsable o liderazgo de servicio. Pero no puede ocultarse que este enfoque de los estudios universitarios no siempre responderá a la demanda, ni de quien acude a un centro universitario, ni de las sociedades de bienestar y opulencia en que vivimos, poco abiertas a integrar a quienes asumen actitudes críticas y audaces frente a sus propias estructuras. En todo caso, insistimos en que las coordenadas del EEES ofrecen oportunidades no despreciables para ello, siempre que se hagan los esfuerzos correspondientes para innovar en los propios planes de estudio y diseño de las competencias. En esta tarea de elaborar planes de estudios habrá que definir un perfil (el modelo de liderazgo) y, si concebimos al líder como el agente de cambio social, habrá previamente que preguntarse a qué tipo de sociedad aspiramos. Educar en la ciudadanía del tiempo que viene, nos llevará a plantearnos y a responder a alguna de estas cuestiones y ahí serán esenciales los liderazgos que se hayan ido formando y configurando ${ }^{16}$. Éstas, tanto más relevantes cuanto que muchas veces se dan por respondidas sin apenas reflexión, nos llevan a la segunda de las grandes cuestiones que planteábamos al comienzo de este editorial: si la universidad en cuanto institución está llamada también a ejercer algún tipo de liderazgo.

\section{La universidad, como institución líder social y cultural}

Hasta ahora hemos hablado de personas que son líderes. ¿̇ale hablar también de líderes institucionales? Si el liderazgo es una tarea tan compleja que hay autores que prefieren hablar de liderazgo más que de líderes, no estará de más plantearse si está función puede ser ejercida por una institución, en nuestro caso por una universidad. ¿̇Está siendo la universidad líder en la transformación social, al menos en España, o va detrás de la misma? No estará de más hacernos estas preguntas cuando asistimos a una crisis de muchas instituciones tradicionales, frecuentemente cuestionadas. Por otra parte, la institución universitaria está sufriendo transformaciones profundas, hasta el punto de que para muchos está perdiendo lo más nuclear de su esencia, el sentido de universalidad del saber ("universidad")

16 Cfr. A. CoRtina ORTs (2007) Ética de la razón cordial. Educar en la ciudadanía en el siglo XXI, Oviedo, Nóbel. Para este tema es particularmente relevante el capítulo 10 sobre la educación en una ciudadanía responsable. Cfr. J. M. Margenat Peralta (2008) (Bibliografía): Revista de Fomento Social $63,547-556$. 
y de diálogo entre distintos saberes científicos. Una universidad así entendida caería en aquella "barbarie del especialista" que ya criticara Ortega Gasset, ${ }_{17}^{17}$ y quedaría reducida a una fábrica de profesionales-técnicos especializados que se forman en centros autónomos y desconectados entre sí, una universidad especie de paraguas que da cobijo a un mundo fragmentado de saberes que se creen autosuficientes. Pues ése es precisamente un serio problema para la formación en un liderazgo de servicio. Si la universidad prioriza la formación de especialistas, logrará personas cerradas y satisfechas, ignaros de sus limitaciones, que por lo mismo que creen dominar un campo de saber, quieren "predominar fuera de su especialidad". Advierte Ortega ante estos sabios-ignorantes que "no escuchan" y se comportan en todo lo que ignoran con toda la petulancia de quien en su cuestión especial es un sabio.

¿Podemos seguir apostando por una universidad que sea espacio para la búsqueda de soluciones a los problemas que acucian a nuestras sociedades? No se trataría, entonces, sólo de mantener y conservar, sino de innovar y abrir nuevos caminos. ¿ $Y$ no es eso lo propio del liderazgo? ¿ Cabe decir que la universidad tiene (o debería tener) un papel de guía de la sociedad o bastaría contentarse, más modestamente, con prestar ese servicio y hacer suyas las demandas profundas de nuestros contemporáneos? Porque la universidad no puede quedar reducida a una "fábrica" de profesionales especializados, sino que tiene que ser consciente de la triple función que le corresponde: ante todo, la generación e investigación del conocimiento, que es la base de la que se nutre todo lo demás; después la formación de ciudadanos, y no solo de profesionales, y, por último, la proyección social, que no sólo incluye la trasferencia de conocimientos, sino la incidencia social.

La tradición universitaria de la Compañía de Jesús ha recibido benéficamente el pensamiento y el testimonio de Ignacio Ellacuría ${ }^{18}$. La institución de la que fue rector durante años, la Universidad Centroamericana José Simeón Cañas de San Salvador, la UCA, en los difíciles momentos en los que una parte importante de sus cuadros fueron brutalmente asesinados en 1989, ha quedado como referente de lo que es un liderazgo institucional y del precio que a veces es necesario pagar por mantenerlo con coherencia.

17 J. Ortega y Gasset (1940) "Misión de la universidad", en El libro de las misiones, Buenos Aires, Espasa-Calpe (Austral 101) 59-129, especialmente pp. 68-86, y J. ORTEGA y GASSET (141954) La rebelión de las masas [1930], Revista de Occidente, "La barbarie del «especialismo»" (capítulo 12), pp. 97-101.

${ }^{18}$ Cfr. Senent de Frutos, J. A. (2010) "La función de la universidad en el pensamiento de lgnacio Ellacuría. Una visión desde nuestro contexto actual": Revista de Fomento Social 65, 657-679. 
Bellamente expresaba Ellacuría su concepción de la universidad con estas palabras que tanto destacan su función social:

El punto de arranque para nuestra concepción de lo que debe ser una universidad viene dado por una doble consideración. La primera y más evidente, que la universidad tiene que ver con la cultura, con el saber, con determinado ejercicio de la racionalidad intelectual. La segunda, ya no tan evidente y común, que la universidad es una realidad social y una fuerza social, marcada históricamente por lo que es la sociedad en la que vive y destinada a iluminar y transformar, como fuerza social que es, esa realidad en la que vive, de la que vive y para la que debe vivir. De ahí surge la cuestión fundamental. ¿En qué consiste el servir universitariamente a la iluminación transformadora de la realidad social, de la sociedad y del pueblo, en que se inserta? ${ }^{19}$

Ellacuría daba el máximo relieve a la proyección social, de modo que ésta determinase últimamente a las otras, aunque también fuera determinada por ellas, y la definía con precisión:

Por proyección social se entiende aquí aquella función que pone a la universidad como totalidad, aunque a través de sus partes, en relación directa con las fuerzas y los procesos sociales. En ese sentido, no se confunde ni con la extensión universitaria, que busca regalar migajas de cultura a grupos que no pueden acceder a la universidad, ni tampoco se confunde con el servicio social, esto es con el trabajo que profesores y alumnos pueden hacer supletoriamente, en favor de determinados grupos sociales. La universidad se pone en contacto con la sociedad de múltiples formas: preparando profesionales, por acciones espontáneas de sus miembros en cuanto no llevan la representación formal o virtual de la universidad, etc. Pero cuando nos referimos a la proyección social, nos referimos a otra cosa: a la incidencia inmediata de la universidad como un todo sobre el todo de la sociedad o sobre algunas de las fuerzas estrictamente sociales ${ }^{20}$.

Tenemos que reconocer que no es esto lo que valoran los "ranking" más consultados en el mundo universitario (por ejemplo, el Shanghai Ranking), aunque no por ello deje de ser un reto más: esforzarse por ser reconocidos internacionalmente a través de esos indicadores, aunque sea una condición elementalmente realista, no puede ser al precio de adaptarse del todo a determinadas demandas que no son muy benévolas ni favorables con quienes reaccionan frente a las injusticias $y$ promueven el cambio social.

\footnotetext{
19 "Discurso de graduación en la Universidad de Santa Clara" (con ocasión de su doctorado "honoris causa" por la Universidad de Santa Clara, California, 1982). Cf. I. EllaCURíA (1999) Escritos universitarios, UCA, San Salvador, 224.

20 I. Ellacuría (1980) "Universidad y política": Estudios Centro-Americanos (ECA) n. 383 (1980) 807-824, reproducido en I. ElLACURÍA (1999) op. cit., 186.
} 
Por otra parte, habría que plantear cuáles son los factores que legitiman a la universidad para liderar el cambio social. La independencia, que es otra forma de llamar a la libertad, es una de esas variables clave para otorgar legitimidad. Pero siempre que vaya unida a la excelencia, en cuanto al desempeño de la función universitaria, que tiene como base fundamental la investigación rigurosa para la generación de conocimiento.

Esta función social o liderazgo social de la universidad va más allá de lo que abarca el concepto de responsabilidad social. Volviendo nuevamente a Ellacuría, y a su maestro Xavier Zubiri, podemos definir la misión de la universidad diciendo que esta debe "hacerse cargo" de la realidad social (dimensión intelectiva), debe "cargar con esta realidad" (dimensión ascética) y debe, finalmente, "encargarse de ella" (dimensión práctica). En el marco de este compromiso ético, social y político con la realidad histórica que fundamenta la misión de la institución universitaria se fundamenta y justifica plenamente la idea del liderazgo social universitario, tanto en sentido institucional, como académico-funcional.

Si el liderazgo implica ponerse al servicio de una causa noble y dejar en un segundo término los propios intereses, ¿̨qué pensar de una universidad endogámica, donde hay escasa participación, donde falta una cultura compartida que vaya más allá

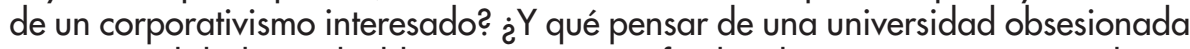
por una calidad acreditable, cuyo "output" final es la posición en un "ranking" determinado, sin reparar si estos "ranking" valoran lo que su misión le obliga a perseguir?

Una universidad no llegará a desarrollar un liderazgo social si sus miembros, la comunidad universitaria entera, y en primer lugar su personal docente e investigador, no comparten esta misión. Hoy el docente se siente con frecuencia poco valorado por los estudiantes, sometido a una burocracia compleja e inmerso en un esfuerzo permanente por armonizar docencia e investigación, situaciones todas ellas que dificultan el sentido de misión.

No podemos dejar de mencionar a profesores que son verdaderos líderes en el aula y en su relación con los alumnos: saben transmitirles, junto con los conocimientos y las técnicas, buenas dosis de espíritu, apertura a los valores y un espíritu inquieto y crítico-constructivo. La vocación universitaria es sobre todo lo que indica la palabra: una vocación que se apoya en verdaderas contribuciones científicas investigadoras, que la sociedad valora y por la que reconoce legitimidad a los docentes y a la universidad, pero se manifiesta además en una coherencia entre lo que dice y lo que hace, de acuerdo con una escala de valores en la que el centro sea la persona. 
Pero el profesor, investigador y docente, es además miembro de una comunidad que comparte un proyecto: ejerce de este modo un verdadero liderazgo que vive no sólo como persona aislada sino como miembro de la comunidad universitaria.

\section{Un liderazgo integrador y complementario: una parábola como conclusión}

A partir de las precedentes consideraciones hemos ido perfilando una definición de un concepto de liderazgo responsable o liderazgo de servicio que sabe ponerse al frente de procesos y cohesionar grupos humanos, institucionales, comunitarios o colectivos como la universidad. Formar para ese liderazgo vendría a ser sinónimo de formar para la excelencia, que no debe identificarse con la brillantez o los resultados: en el liderazgo la apariencia o la comunicación externa, aún siendo importantes, no son lo definitivo. Existen muchas veces liderazgos que no dudaríamos en llamar anónimos, de los que al comienzo del editorial hemos dado alguna referencia, y otras veces liderazgos complementarios unos de otros. Para concluir presentamos una parábola en la que podemos reconocer cuatro formas esenciales de liderazgo, a la vez que el carácter colectivo y complementario que en todo liderazgo tiene cada uno de sus componentes. Esta parábola podría servir como instrumento de evaluación del ejercicio del liderazgo en una institución y, ciertamente, para saber si la universidad está formando a los estudiantes como líderes y está ejerciendo el liderazgo institucional social y cultural a que nos hemos referido.

El filósofo, y profesor en Tubinga, Ernst Bloch, en una conferencia a finales de los años 60, se refería a los carismas de un pueblo en marcha, cuatro carismas fundamentales para constituirse como pueblo y para hacer un camino ${ }^{21}$. Esta parábola, de indudable raigambre bíblica, puede servirnos para concluir esta reflexión, resumiendo la doble característica del liderazgo para el cambio social y la transformación del mundo, para formar y descubrir una ciudadanía y una profesionalidad al servicio de la justicia. Benito Espinosa, el filósofo judío holandés de origen sefardí, en su Ética defiende una transversalidad integral del dinamismo interno de toda comunidad, junto a la complementariedad que

${ }^{21}$ Existen diversas transmisiones orales de aquella conferencia, así como recreaciones posteriores todas ellas fácilmente accesibles en la red, aunque parece que el texto quedó reflejado en un artículo posterior de Bloch. Según J. A. García, uno de los transmisores de la versión oral recibida a través de A. Álvarez, la conferencia se subtitulaba: "¿Con qué dinamismos interiores ha de estar habitada una colectividad para que sea capaz de crear historia?". 
deben ejercer los sujetos históricos dentro de la misma. Cualquier pretensión de monopolizar por parte de uno de ellos, sea una clase social, una raza, un poder político o una confesión religiosa, todo el dinamismo social, habría de llevar inexorablemente a alguna forma de totalitarismo o de reduccionismo. Sólo en la pluralidad, y en su articulación ordenada, cabe desplegar en la colectividad aquellos dinamismos interiores, aquellas virtudes y aquellos carismas, de manera que aquélla sea capaz de crear procesos de orientación y prácticas de transformación social que hagan avanzar el umbral de lo real posible y la conciencia de la dignidad humana. Para ello, una sociedad necesita de lo profético, lo cantor, lo medicinal y lo regio.

Lo profético. El profeta ve lo que el grupo todavía no es ni puede ver y llama insistentemente a aquél a ponerse en marcha hacia una tierra nueva. Una comunidad sin este carisma, sin este liderazgo, pierde su capacidad de analizar el presente y de abrir posibilidades hacia el futuro. "Lo profético" denuncia las comodidades consentidas, las causas del mal, las connivencias ideológicas y los intereses ocultos y deja todo al descubierto. Los profetas son personas, y a veces grupos, antipáticos, soñadores, exigentes, descorazonadores o poco realistas, por lo que desenmascaran el narcisismo instalado y conservador -también el narcisismo ilustrado sólo retóricamente progresista-y proponen y reproponen ese "plus" que hay que conquistar si tienen que seguir existiendo posibilidades con dignidad y con calidad humana.

Lo cantor. Los profetas a veces hablan confusa, enrevesada u oscuramente. En el pueblo en marcha debe haber quien traduzca para todos lo que sólo algunos son capaces de entender o de ver. Los cantores han desempeñado ese papel. Son mujeres y hombres dotados de la capacidad narrativa que formula interpretaciones con sentido para las biografías personales y colectivas. El cantor no se detiene en lo no alcanzado, sino que prefiere recordar aquellos orígenes de los que parte el éxodo, subraya lo alcanzado y propone imágenes atractivas de la tierra de promisión a la que se saben convocados. Los cantores tratan de configurar narraciones de acuerdo con las virtudes que fortalecen y orientan sus esfuerzos, señalan hitos, reconocen paisajes y sueñan horizontes. El cantor y la cantora, los cantores, deben animar la marcha, haciéndola bella, atractiva y deseable. Son los hermeneutas, las comunidades de memoria o los creadores de significados que captan y saben cantar los ideales históricos desde la amistad cívica generadora de fraternidad y desde la imaginación social, desde la invención democrática y desde la capitalización social tan necesaria para un bien común sosteniblemente buscado y justo. Lo cantor hace posible y creíble lo que anuncia lo profético. 
Lo medicinal. Este liderazgo puede ser más neutro, puede ser grupal o personal, femenino o masculino, ágrafo, silente o publicado, admite varias combinaciones, pero se ocupa de algo esencial: sanar. En el camino de una sociedad en búsqueda, de una empresa en marcha, de un colectivo que lucha por la justicia y sueña la fraternidad, aparecen roces y heridas, hay cansancio o decepción, siempre hay gente que sufre $y$, por ello, hacen falta personas que, aunque aparentemente no tienen un rol fundamental, saben acercarse a la persona herida y desanimada y alentarla a seguir adelante. Cuando la diferencia entre las fuerzas reales y los retos marcados se hace angustiosa, entre los esfuerzos y los logros, hay un carisma, un ejercicio de liderazgo transaccional, complementario y esencial para el ejercicio del liderazgo transformacional. El primero tiene que saber alentar en las horas de cansancio y hacer recuperar el aliento a los enfermos y a los prescindibles. Quienes tienen a su cargo ese carisma, ese liderazgo, han de fortalecer resistencias, con prudencia y paciencia, y curar aquellas otras resistencias que frenan, bloquean o desorientan. Todos no pueden resistir con igual fortaleza las exigencias de la marcha y las heridas profundas del alma. Sin lo medicinal el carisma de lo cantor deviene retórica y lo profético es bloqueo y angustia.

Lo regio. Éste es el último carisma de la parábola y no el menos necesario. Lo regio está encarnado por una persona o por una institución, un colectivo o un equipo, que son capaces de articular los otros liderazgos para un ejercicio justo de cada uno de ellos al servicio del bien común. Quien ejerce ese carisma es aquel a quien en realidad llamamos o pensamos como líder, como la persona -o el grupo- capaz de formular una visión y unos objetivos y de contagiar entusiasmo ante una visión compartida y equilibrada. El liderazgo "regio" representa el servicio de la autoridad, necesaria en toda comunidad como auctoritas, es decir como capacidad para crecer y hacer crecer las mejores posibilidades para el bien común de todos y de cada uno, el bien común integral resultado del desarrollo de toda la persona y de todos. Cuantas más y mejores presencias carismáticas haya en un pueblo, más relevante y necesario es el carisma de "lo regio". Sin ese servicio el mundo interior de la comunidad puede degenerar en caos cacofónico, mientras que "lo regio" se parece al buen director de orquesta que obtiene los mejores resultados de cada instrumentista logrando un desarrollo sinfónico de los demás liderazgos.

Los equilibrios y el dinamismo interno de estos carismas son necesarios para ese liderazgo transversal en una sociedad, una institución, un cuerpo político o en la familia humana entera. Todos los liderazgos son convenientes y serviciales al conjunto, aunque es tarea del liderazgo regio cuidar la complementariedad y el servicio de los demás liderazgos. Ésa es la responsabilidad del liderazgo que la universidad tiene como misión formar y que la universidad en cuanto institución debe ejercer. 